\title{
GONÇALVES, Cristiane Souza. Restauração arquitetônica: a experiência do SPHAN em São Paulo 1936-1975. São Paulo: Annablume, 2008.
}

\section{Tami Coelho Ocar}

E-mail: tami.c.ocar@gmail.com
Graduanda em História pela Universidade Estadual de Campinas e colaboradora do Laboratório de Arqueologia Pública Paulo Duarte - NEPAM/Unicamp.

Formada pela Universidade Federal do Espírito Santo, a arquiteta Cristiane Souza Gonçalves se especializou em Patrimônio Arquitetônico: Teoria e Projeto pela PUC - Campinas, no ano de 1999. Em 2004 fez seu mestrado em Arquitetura e Urbanismo, pela FAU - USP, sob a orientação da Profa. Dra. Maria Lucia Bressan Pinheiro. Tornou-se doutora em 2010, também sob a tutela de Bressan Pinheiro, seguindo o mesmo programa. Atuou como colaboradora da Kruchin arquitetura desde 1999. Atualmente trabalha na Coordenação-geral de Pesquisa e Documentação do IPHAN. A publicação de "Restauração arquitetônica: a experiência do SPHAN em São Paulo 1936-1975" é fruto de sua dissertação de mestrado.

Neste livro a autora analisa o trajeto de algumas das intervenções de restauro realizadas pelo SPHAN - Serviço do Patrimônio Histórico e Artístico Nacional - durante o período compreendido entre 1937 e 1975, época em que a diretoria do órgão paulista estava a cargo do engenheiro arquiteto Luis Saia, sucessor de Mário de Andrade. Para isso, a ela se utiliza de quatro exemplos de intervenções: na década de 30 foi selecionada a Igreja de São Miguel Paulista - tombada em 1938 pelo IPHAN, na década de 40 foi a restauração do Sítio e Capela de Santo Antônio - tombados em 1941 pelo IPHAN; a Casa de Câmara e Cadeia na década de 50 - tombada em 1955 pelo IPHAN.; e por fim, na década de 60, ela escolheu tratar sobre a Fazenda Pau D'Alho - tombada em 1968 pelo IPHAN.

Gonçalves divide seu livro em duas partes, sendo que primeiramente ela trata desde os primeiros sentimentos de preocupação quanto à defesa do patrimônio cultural brasileiro, que começaram a surgir no século XVIII; até o nascimento do SPHAN, então sob a tutela de Mário de Andrade, mostrando através de cartas e documentos como se deu a criação de um órgão de proteção ao patrimônio cultural nacional e, no geral, como sucederam as primeiras ações em defesa desses bens nacionais. Ela então analisa a fase heroica de Luis Saia em São Paulo, para finalmente poder tratar, na segunda parte, as obras escolhidas por ela. O estudo de cada bem foi dividido em duas etapas: preliminar investigações, prospecções e pesquisas históricas, sendo essas documentais e orais, em torno do bem -; e executiva - que consiste em projeto, plano de obras e procedimentos de trabalho. 
Ela começa tratando sobre a restauração da Igreja de São Miguel Paulista (1939 - 1941). Construída no século XVII, foi considerada por Mário de Andrade um documento importante da arquitetura paulista e "uma das relíquias históricas do Estado" por ser uma das poucas igrejas com alpendre frontal. Juntamente com o Convento de Embú, a intervenção à igreja inauguraria o modo que Luis Saia utilizaria para restaurar os bens de sua época de direção do SPHAN: a ideia de retomar o "original" através de métodos tradicionais paulistas. No caso da Igreja de São Miguel essa técnica foi utilizada apenas no corredor lateral, porém é o "ponto de partida" desse modo de restauro utilizado por Saia, que pretendia manter as paredes de taipa, retirando inclusive o apoio delas, feito de alvenaria de tijolos e que lá estava desde uma reforma anterior. Para substituir os tijolos ele inaugura um procedimento: decide inserir uma estrutura de concreto armado para reforçar as paredes de taipa. A partir daí o SPHAN passa a utilizar amplamente esse método de intervenção, dentro e fora de São Paulo. A autora salienta que a escolha do concreto deu-se, sobretudo, por uma questão de mostrar a modernidade. Porém, apesar do desejo de Luis Saia de que a Igreja se mantivesse "original", ela nunca voltaria a ser o que era, pois qualquer intervenção que se fizesse - ou que se faça - estaria repleta de conceitos contemporâneos, tanto materiais quanto morais.

Após tratar da Igreja de São Miguel Paulista, Cristiane Souza Gonçalves aborda outra intervenção que também empregou novas técnicas de trabalho: a restauração da casa-sede e capela do Sítio Santo Antônio, que se deu entre os anos de 1940 a 1947. Esse conjunto, localizado em São Roque, encantou Mário de Andrade, por sua "monumentalidade paulista", seu valor artístico e, sobretudo, histórico- o complexo foi construído por volta de 1681. Encontrada em ruínas, o seu processo de restauro foi um desafio para os técnicos do SPHAN. As principais intervenções foram: demolição da casa do Barão, que ficava ao lado da casa-grande; reconstituição do alpendre frontal da capela e a reconstrução da ala esquerda à casa-grande. O concreto armado foi também amplamente utilizado nessa intervenção, tanto nas vigas e pilares, utilizados como esqueleto nas consolidações de taipa já existente, quanto na ala da casa-grande, sendo que para essa reconstrução foi utilizado o concreto ciclópico, que apresenta semelhanças com a taipa, tanto em relação à execução quanto ao aspecto final. Outra novidade que marcou essa intervenção foi a elaboração de uma maquete de estudos da capela.

A terceira restauração escolhida foi a da Casa de Câmara e Cadeia de Atibaia (1958 - 1961), que na década de 50 sofria a iminência de ser demolida. A autora destaca que é pequena a quantidade de documentos sobre esse bem, se comparado aos outros prédios estudados, o que pode ser explicado pela pressa que se teve em tombá-lo, pois o SPHAN não teve tanto tempo para fazer uma pesquisa minuciosa a cerca do edifício - tendo em vista que o prédio estava prestes a ser demolido -, e isso acabou por acelerar a burocracia interna para seu tombamento. Logo, sem essa pesquisa, foram necessárias prospecções no local para que se pudesse reformar, sendo que as escavações poderiam levar a considerações errôneas sobre a arquitetura do bem. Para que isso fosse resolvido da melhor maneira, Luis Saia conduzia as prospecções a partir de suas proposições de restauro, tornando assim, a restauração numa reconstrução, pois, devido à ausência documental, Saia acabou por transformar a Câmara e Cadeia em um prédio de aparência colonial, mandando inclusive demolir a torre 
sineira e remover os revestimentos externos, frutos de uma reforma passada. Isso se deu por que ele afirmava que a construção era de taipa, e sendo de taipa não era passível de tais liberdades de reforma, o que acabou por gerar uma série de discussões sobre o material - tijolo ou taipa - que poderia ter sido utilizado para a construção da Casa de Câmara e Cadeia de Atibaia. Apenas no ano 2004 foram feitas prospecções mais profundas que identificaram os materiais: parede externa de tijolos, com um vão no meio preenchido com pedras, cacos de cerâmica e terra; parede interna, da antiga cela posterior, em taipa de pilão; e parede interna do pavimento superior, junto à escada, de pau-a-pique.

A autora afirma que havia um sentimento de negação quanto à possibilidade de ter-se utilizado tijolos para a construção do prédio, pois "reconhecer a presença dos tijolos seria enfraquecer a ideia do monumento colonial que se queria restaurar" (2008: 153). Essa repulsa ao modelo eclético não era exclusivamente paulista, mas sim permeava, no geral, os trabalhos da diretoria em todo território nacional. Assim, diferente dos outros dois exemplos de intervenções já citados, a importância e a escolha dessa "reconstrução" se deu, sobretudo, pelo modelo estruturador que permeava as ações do SPHAN, e não tanto por conta das análises técnicas.

Como último monumento escolhido, Gonçalves discorre sobre a intervenção feita à Fazenda Pau D’Alho (1969 - 1975). Localizada no Vale do Paraíba, essa construção típica das primeiras residências cafeeiras causou uma forte impressão na direção da regional, fosse por sua monumentalidade, pela paisagem ou até mesmo pela qualidade de seu conjunto arquitetônico; e, apesar de ter sido inventariada em 1942, só passou por uma intervenção após o seu tombamento, em 1968. Infelizmente a fazenda sofreu uma forte deterioração durante esses 30 anos em que "aguardou" para ser tombada. Dentre os principais danos que a fazenda sofreu durante esse longo período de negligência estavam o desaparecimento da tulha e da roda d'água, que em 1942 já apresentavam apenas as fundações, e a deterioração quase completa da senzala, casa do administrador e depósitos. Logo, as ações básicas realizadas na Fazenda Pau D'Alho foram as "reconstruções" das dependências desaparecidas e a consolidação dos segmentos que, de forma precária, ainda se mostravam visíveis. Foi novamente utilizado o concreto ciclópico para a reconstituição dos locais que originalmente haviam sido construídos em pedra argamassada como os embasamentos da casa sede, tulha, roda d'água e a escada de acesso a senzala. Já para as estruturas de pau-a-pique - utilizado praticamente de forma integral nas vedações - optou-se por uma reconstituição através de materiais similares, sendo o preenchimento do núcleo feito com tijolos dispostos em "espelho" e argamassa de cimento. A autora afirma que é impossível distinguir as estruturas originais das reconstituídas após os acabamentos de revestimento e pintura, apesar das intervenções terem sido feitas com materiais diferentes dos utilizados na construção do prédio, pois estas acabavam por ter o mesmo tratamento que era utilizado nas estruturas remanescentes.

Por fim a autora destaca quatro noções que ela considera fundamentais para uma discussão mais atenta, a fim de identificar as características da diretoria de Luis Saia no SPHAN, em relação aos processos das quatro intervenções estudadas. São elas: noção de unidade estilística; diferenciação dos materiais utilizados nas intervenções; a visão modernista e as ações do SPHAN; e, por último os procedimentos específicos de trabalho da regional paulista. No primeiro 
ponto a autora afirma que o pensamento violletiano teve forte influência na regional paulista do SPHAN. Como exemplo disso temos o Sítio Santo Antonio, onde se recuperou o conjunto do século XVII - refazendo a ala desaparecida da sede - e suprimiu-se o que era posterior - a casa do Barão, feita no século XIX. Outro componente vital do pensamento de Viollet-le-duc e que foi aplicado pelo SPHAN é a busca pelos "modelos abstratos", que se deu através de um estudo sobre a arquitetura do período colonial, a fim de se recuperar aquilo que estava perdido. Essas pesquisas trouxeram maior entendimento sobre o tema da produção arquitetônica colonial paulista. Apesar disso Gonçalves afirma que apenas esses estudos não foram o suficiente para conhecer historicamente como era o edifício em si, mas sim apenas a arquitetura tradicional, fazendo com que o prédio restaurado, por fim, se distanciasse da sua realidade histórica.

Além de Viollet-le-Duc, tivemos também Camilo Boito, teórico do século $X I X$, influenciando a regional paulista do SPHAN, através de seu pensamento de mínima intervenção à obra, a fim de garantir sua integridade e autenticidade. Como exemplo disso tem a Igreja de São Miguel Paulista - onde foram reparados os elementos internos não artísticos e consolidadas as taipas. $\mathrm{Na}$ parte de diferenciação dos materiais utilizados nas intervenções, Cristiane Souza Gonçalves discorre sobre o uso intensivo do concreto armado por parte de Luis Saia, que pode ser explicado tanto pela teoria de Boito - em que ele afirma que o material para restauração deveria ser diferente do material original, para que se pudesse distinguir a intervenção realizada da obra já existente, evitando, assim, a perda de autenticidade do documento (2008: 194) - quanto pode ser explicado também pelo pensamento violletiano, o qual explica que nas restaurações deve-se substituir a parte retirada por um material mais resistente, afim de que a vida-útil do monumento seja mais longa, e também que se desse um melhor acabamento. Com isso temos o embate entre a caracterização do original para o restauro versus a unidade de conjunto. No final as diferenciações, restritas apenas nas estruturas dos prédios, foram "encobertas" pela unidade formal e estilística colonial, que se deu através de camadas de revestimento e pintura. Logo, a primeira vista, nem se percebe que houve uma intervenção.

Com isso, a autora chega ao terceiro ponto: a visão "modernista", que através dessas restaurações feitas de concreto e baseadas em Viollet-le-Duc e Boito, conduziriam a produção arquitetônica a partir daquele momento. $O$ uso do concreto armado, a valorização do traço geométrico e o resgate ao modelo colonial foram as principais ações modernistas do SPHAN. Enfim, Gonçalves destaca alguns procedimentos específicos utilizados nas quatro intervenções estudadas e que passariam a constituir um modo de trabalho singular da regional paulista. Ela ressalta, em primeiro lugar, o fato de que as etapas de projeto e pesquisa não foram claramente definidas, sendo ambas realizadas totalmente e preliminarmente ao início das obras. Isso é absolutamente justificável, pois a restauração do patrimônio arquitetônico, dada através do SPHAN, era então um pioneirismo no Brasil. Apesar disso os trabalhos seguiram uma sequência de procedimentos específicos, sendo que estes se repetiriam a cada obra iniciada pelo SPHAN. Essa aproximação da diretoria do órgão com Viollet-leDuc, através da tentativa de estabelecer uma sequência de trabalho, também é um ponto crucial na metodologia da regional paulista. Outro procedimento - possivelmente inaugurado pela regional - foi a utilização de concreto armado na estrutura das obras. Por fim, ela ressalta que essa época do SPHAN trata-se de um período de pioneirismo na história da arquitetura brasileira, principalmente 
pelo fato de não ter-se cumprido uma metodologia específica de trabalho, dadas as dificuldades das condições da época, do acesso aos arquivos documentais e, portanto, uma dificuldade maior para intervir às edificações.

Durante todo o livro a autora faz um percurso minucioso através de seu recorte histórico escolhido. Descrevendo detalhes dos edifícios e suas técnicas de restauro, se utiliza muitíssimo bem de diversos tipos de fontes, sobretudo de fotos, plantas, cartas, arquivos e entrevistas. Para se aprofundar melhor em questões físicas da arquitetura ela utiliza-se de obras básicas, como Restauração, de Violet-le-Duc; e Os Restauradores, de Camilo Boito; até bibliografias mais específicas da arquitetura paulista, como por exemplo, Evolução urbana de São Luis do Paraitinga, do próprio Luis Saia; e Construções de taipa - alguns aspectos de seu emprego e da sua técnica, monografia de Carlos Borges Schmidt. Com muita habilidade ela mantém um diálogo entre o leitor e o SPHAN do início do século $X X$, sempre citando os documentos em que pesquisou, sobretudo as cartas trocadas entre Luis Saia e seus colegas - que mostram muito bem o pensamento moderno da época - e fontes iconográficas. Isso além das ótimas plantas do edifício, onde nos é mostrado um "antes e depois", o que facilita muito o entendimento das construções e as intervenções sofridas. Na última parte Gonçalves faz uma comparação interessante, colocando duas fotos de cada prédio, uma tirada antes da intervenção - pelo SPHAN -, e outra foto mais atual. Assim ela nos mostra que existem muitas diferenças entre o antigo e o que passou por intervenção, por mais que Luis Saia desejasse manter o original. Esta obra é excelente e indispensável para qualquer pessoa que deseja obter alguma formação em patrimônio histórico e cultural, sobretudo quanto às intervenções e modelos de restaurações dos primórdios do SPHAN. 